\title{
REPRESENTAÇÕES SOCIAIS DA INFÂNCIA INDÓCIL: ANÁLISE DOS REGISTROS NOS LIVROS DE OCORRÊNCIA EM UMA ESCOLA MUNICIPAL DE SANTA MARIA, RIO GRANDE DO SUL
}

\author{
SOCIAL REPRESENTATIONS OF INDOOR CHILDREN: \\ ANALYSIS OF RECORDS IN THE BOOKS OF OCCURRENCE IN A MU- \\ NICIPAL SCHOOL OF SANTA MARIA, RIO GRANDE DO SUL
}

\author{
SibILA LuFT ${ }^{1}$
}

Recebido em: 07/04/2016

Aprovado em: 12/09/2016

\section{RESUMO}

Este artigo objetivou conhecer as representações produzidas no espaço escolar sobre os alunos indóceis. Para isso, desenvolveu-se, por meio de uma pesquisa de cunho qualitativo, uma análise documental nos livros de registro de ocorrência, envolvendo alunos dos anos iniciais de uma escola da rede municipal de Ensino Fundamental da cidade Santa Maria, Rio Grande do Sul, tendo sido analisados 743 registros, em cinco livros, de junho a julho de 2011. Para a análise e interpretação dos dados coletados, empregou-se a análise de conteúdo, e, com o aporte teórico da Teoria das Representações Sociais, buscou-se conhecer as representações formadas e seu impacto nas práticas de in/exclusão. No contexto pesquisado, os alunos que apresentam comportamentos como indisciplina, agressões a colegas e desacato à professora são os mais vulneráveis à exclusão do espaço escolar. As medidas e os procedimentos adotados pela escola nesses casos incluem exclusão de forma fracionada, por dias; ameaças de exclusão, representada na forma de transferência dirigida para outra escola; ameaça de exclusão de projetos sociais; e negação do direito de assistir a aulas de determinadas disciplinas.

Palavras-chave: Representações Sociais; Infância Indócil; Educação; Livros de Ocorrência.

\begin{abstract}
This article aimed to know the representations produced at school on unruly students. For nails, developed from, through a qualitative approach research, a documentary analysis in the occurrence registration books, involving students in the early years of a School Municipal Network Teaching Primary City Santa Maria, Rio Grande do Sul, severed Muncul analyzed 743 records in five books, june july 2011. for the analysis and interpretation of the collected data, we used the content analysis, and with theoretical support the Social representation Theory, sought to know the representations formed and its impact on the practices in/exclusion. In the researched context, students with behavior such as indiscipline, aggression to disrespect the teacher colleagues are the most vulnerable we exclusion on school space. The safety and procedures adopted Pella school in these cases include exclusion in divided doses for days; threats exclusion, represented form of transfer directed to another school; threat exclusion to social projects; denial of the right to attend classes for certain subjects.
\end{abstract}

Keywords: Social Representations. Childhood restive. Education. Occurrence of books.

\footnotetext{
1 Doutora em Educação pela UFSM. Psicologia/UCPEL (1996). Docente nos Cursos de Graduação e Pós-Graduação da Universidade Regional Integrada do Alto Uruguai e das Missões - URI/Santiago/RS. E-mail: siluft@hotmail.com 


\section{Introdução}

Sendo a categoria "infância" uma construção social, as representações sobre tal categoria se alteram conforme as mudanças sociais, culturais, históricas, políticas e econômicas ocorridas em determinado contexto. $\mathrm{O}$ surgimento da leitura e da escrita, vital para o progresso civilizatório e para a sobrevivência da cultura, influenciou a criação da instituição escolar, com uma nova representação de criança: o gentleman e o pequeno burguês, a partir do século XVII (ARIÉS, 1981; POSTMANN, 1999). A instituição escolar foi, então, nomeada e autorizada como agente formador no processo educativo das diversas etapas da vida humana.

Com foco principal na infância, algumas pesquisas (ARIÉS, 1981; POSTMANN, 1999; CORAZZA, 2000; FOUCAULT, 1987; PATTO, 1996; PASSETTI, 2007; SANTOS, 2007; DEL PRIORE, 2007; ROUSSEAU, 1979) evidenciam que desordeiros, indisciplinados, problemáticos, incorrigíveis, anormais, criminosos, foras da lei e os de temperamento difícil e indócil são citados no meio educacional desde o seu surgimento. Diante disso, este artigo objetivou conhecer as representações produzidas no espaço escolar sobre os alunos indóceis, por meio de uma pesquisa de cunho qualitativo, envolvendo alunos dos anos iniciais de uma escola da rede municipal de Ensino Fundamental da cidade Santa Maria, Rio Grande do Sul.

\section{Fundamentação Teórica}

\subsection{A produção da infância: de indócil à infratora}

Tendo em vista a importância da educação e dos vínculos familiares na formação do homem, Rousseau (1979) afirma que "a educação primeira é a que mais importa" (p. 9). O filósofo propõe, ainda, uma reflexão sobre a educação da infância indócil:
Considero impossível que se possa trazer ao seio da sociedade uma criança de doze anos sem lhe dar alguma idéia das relações entre homem e homem e da moralidade das ações humanas... Há temperamentos dóceis e tranquilos que podemos levar longe sem perigo para a sua inocência primeira; mas os há também violentos cuja ferocidade se desenvolve cedo e que precisamos apressar-nos em deles fazer homens para não sermos obrigados a acorrentá-los (ROUSSEAU, 1979, p. 84, grifo do autor).

Ao abordar a questão das relações e ações humanas para o convívio em sociedade e dos distintos temperamentos das crianças, Rousseau (1979) alerta para a educação de crianças de temperamentos distintos, afirmando que para os dóceis e tranquilos não há perigo, visto serem estes o tipo de aluno representado no imaginário dos educadores, que é fácil de educar, que não gera problemas nem conflitos.

Também existem, contudo, os alunos reais, os indóceis, ou seja, aqueles em que a "ferocidade se desenvolve cedo", para os quais o filósofo alertava que era preciso "apressar-nos em deles fazer homens", caso contrário, logo a sociedade deveria colocar-lhes outros limites (ROUSSEAU, 1979, p. 85). Necessita-se educar a criança para viver em sociedade, mas:

Se ousar bater seriamente em alguém, seja seu lacaio, seja seu verdugo, fazei com que lhe devolvam os golpes com juros, de maneira a tirar-lhe a vontade de recomeçar (ROUSSEAU, 1979, p. 85).

Não permitir abusos das crianças e revidar a agressão sofrida foi à proposta de educação para a infância indócil, a qual emergia em uma sociedade sob os ideários da revolução, precursora dos direitos do recém-criado "cidadão". No entanto, a esse respeito surgiram alguns questionamos, tais como se não seria 
essa educação mais punitiva do que a Lei de Talião, uma das leis mais antigas existentes, que "impunha limites à reação do ofendido. Este não podia causar mais mal ao ofensor do que aquele mal que havia sofrido" (MEDEIROS, 2011, p. 15). Sob essa ótica, uma ação comportamental indesejada deveria ser revidada com a mesma punição, e não "com juros", como propôs Rousseau.

Manacorda (2006, p. 33), ao pesquisar sobre a educação do aluno indisciplinado, aponta documentos que remetem ao Período do Novo Império (1552-1069 a.C.), os quais indicavam que "as punições corporais" consistiam em métodos utilizados para o aprendizado, sendo constantes as comparações dos jovens indisciplinados aos "animais rebeldes que precisam do chicote para ser domesticados, sendo que as surras não vinham sozinhas, eram acompanhadas da reclusão e dos grilhões".

Cabe ressaltar que a disciplina foi utilizada em muitos momentos da história da educação como método coercitivo, mas não a disciplina tal qual a compreendemos atualmente. Tratase daquela à que Manacorda se refere como um instrumento utilizado para a punição corporal dos alunos: "um bastão de 8 a 9 polegadas, na ponta do qual estão fixadas 4 ou 5 cordas e cada uma delas terá na ponta três nós" (2006, p. 234 apud LA SALLE, 1720, p. 147).

A constituição do campo educacional remete às representações de obediência: punições corporais, surras, clausura, reclusão, vinganças, morte do mestre, chicoteamento, escravidão, espionagem, vigilância, controle, delação, mentiras, disciplina, sacrifícios, trabalhos contínuos e forçados, anarquia, desordem e agressão (MANACORDA, 2006; FOUCAULT, 1987; ROUSSEAU, 1979; JAEGER, 1995). Isso ocorre até o século XIX, quando surge uma nova concepção de infância, precedida pela Convenção de 1793 , realizada na França (JODELET, 2009; ARIÉS, 1981).
São criadas, nessa época, novas representações sobre a infância pobre, ou seja, aquela que não foi excluída de determinado espaço porque não havia ocupado este espaço (o escolar), mas, quando ocupá-lo, irá causar estranheza aos mestres. No contexto atual, por intermédio da legislação, a infância "sai" da fábrica e "vai" para a escola, passando a ter seu direito assegurado, com todos os estranhamentos do professorado sobre quem é o novo aluno. Assim, criam-se novas representações.

Repensar o mal-estar gerado pela infância indócil implica aos adultos repensar suas responsabilidades para com a infância na atualidade, não esquecendo, portanto, os legados sócio-históricos e culturais de como estas demandas foram sendo construídas e representadas no decorrer dos séculos. Com o advento da infância infratora, os olhares dos juristas passam para essa nova categoria, pois se fazia urgente a criação e implantação dos tribunais para os menores, seguindo os mesmos moldes daqueles já criados para os adultos envolvidos com problemas judiciais.

$\mathrm{Na}$ educação, mais especificamente na educação especial, os distúrbios de conduta são pouco pesquisados: "persistem lacunas, faltando respostas para solucionar a questão da exclusão social e educacional das crianças emocionalmente perturbadas" (NAUJORKS, 2001, p. 12). Nesse sentido, um dos aspectos que chama a atenção diz respeito à quantidade de nomeações e renomeações que existem para os alunos com comportamentos indóceis: Condutas Típicas, Distúrbios de Conduta, Comportamentos Atípicos, Transtornos Globais do Desenvolvimento e Problemas de Conduta, por exemplo (OMS/CID-10, 1993; KAPLAN, 2002; BARKLEY, 2002; ROHDE; BENCZIK, 1999; ROHDE; MATTOS, 2003; ROHDE et al., 2004).

Um dos marcos históricos a esse respeito, que registra o início dos olhares para a educação da infância emocio- 
nalmente perturbada e abandonada, tendo envolvido amplas discussões com a participação de diversos atores sociais, dentre os quais filósofos, cientistas, médicos e cidadãos comuns da sociedade francesa, e resultado na obra $A$ Educação de um Selvagem, foi o trabalho do médico Jean Itard (BANKS-LEITE; GALVÃO, 2000).

No Brasil, Mazzotta (2005) refere que o atendimento da criança com problemas de conduta era efetuado por professores da rede estadual, no Instituto Pestalozzi, criado em Belo Horizonte no ano de 1935 , com a contribuição da professora Helena Antipoff. A terminologia problemas de conduta também aparece no Regimento Interno, artigo $2^{\circ}$, do Centro Nacional de Educação Especial (CENESP), criado pelo Decreto n. ${ }^{\circ}$ 72.425/73 (MAZZOTTA, 2005, p. 55). No ano de 1993, na Política Nacional de Educação Especial (PNEE), consta a terminologia condutas típicas (problemas de conduta) ${ }^{2}$, época em que, segundo Mazzota (2005, p. 24), "se substituiu a denominação problemas de conduta por portador de condutas típicas" (grifo do autor).

Sobre a educação de crianças violentas e em vulnerabilidade social, existem alguns trabalhos dos médicos Winnicott (2005) e Korczak (1997). Este afirmava que "a medicina não estava preparada para tratar das complexas questões sociais e educacionais presentes na vida das crianças, principalmente daquelas em situação de risco" (KORCZAK, 1997, p. 48).

Nas ciências médicas, além da categoria dos transtornados, mas medicados, (LUFT, 2007) criada pela medicina, responsável por tratar os sujeitos à base de cloridrato de metilfenidato ${ }^{3}$, uma substância psicotrópica que atua diretamente no sistema nervoso central, contribuindo para o aumento da atenção e da produtividade do aluno, a

2 MEC, Secretaria de Educação Especial. Política Nacional de Educação Especial. Brasília, MEC/SEESP, 1993.

3 O cloridrato de metilfenidato é comercializado no Brasil com os nomes Ritalina e Concerta. mais nova categoria criada com amparo legal (Lei n. ${ }^{\circ}$ 8.069) é a dos infratores, mas assistidos. Estes foram inclusos em um "programa comunitário ou oficial de auxílio à criança e ao adolescente" (BRASIL, 1990), que previa "matrícula e frequência obrigatórias em estabelecimento oficial de ensino fundamental" (BRASIL, 1990). Assim, as ciências jurídicas ampliam-se e expandem seu poder de atuação para o espaço escolar, sob a prerrogativa do discurso de proteção da infância.

O saber e o poder médico tornamse gradativamente incontestáveis, de modo que cada vez mais os profissionais dessa área irão delimitar seu campo de atuação, sendo consolidada a sua importância principalmente no campo das instituições (Rizzini, 2009). Nesse mesmo período, a Justiça lança seu olhar à descoberta dos viciosos e delinquentes: são criados para estes os reformatórios e as casas de correção, com o discurso da reeducação em detrimento da punição, tendo como aliados a Medicina Higienista e a Psicologia, que almejava uma nova formação do homem. Assim, a Justiça, aliada ao aparato assistencial e aos novos saberes científicos, vislumbra o atendimento para a juventude viciosa e delinquente (RIZZINI; PILOTTI, 2009). A reeducação passa a ser percebida como um meio de ressocialização da criança e do adolescente marginalizados.

Para Rizzini e Pilotti (2009), durante a expansão fabril no século XIX, aos moldes do que havia ocorrido na Europa, era fundamental a garantia de mão de obra barata, momento em que as portas das fábricas são abertas também para as crianças pobres. Estas, juntamente com as mulheres, irão representar a grande massa de trabalhadores (PILOTTI, 2009) do período - o discurso vigente dos patrões para justificar a exploração do trabalho infantil era retirar as crianças da ociosidade.

Logo, encontrar ocupação para as crianças asiladas era uma forma de resolução de alguns problemas sociais 
emergentes, como, por exemplo, alimentar as fábricas desprovidas de recursos humanos, contribuindo, assim, para os lucros do empresariado brasileiro. Dessa forma, ocorre a construção da representação da infância ociosa brasileira, fato que só muda, quando mais tarde, ocorre a abertura de outro espaço: o espaço escolar.

\section{Metodologia}

Com o aporte da Teoria das Representações Sociais, que tem como principal função, segundo Moscovici (2010, p. 20), "tornar algo não familiar, ou a própria não familiaridade, familiar", efetuou-se uma pesquisa documental, aprovada pelo Comitê de Ética em Pesquisa sob n. ${ }^{\circ}$ 0287.0.243.000$11 / 2011$, de acordo com a resolução do Conselho Nacional de Saúde (CNS) n. ${ }^{\circ}$ 196/96. A pesquisa foi realizada em uma escola municipal de Ensino Fundamental da cidade de Santa Maria, Rio Grande do Sul, sendo utilizados cinco livros de registros de ocorrência envolvendo alunos dos anos iniciais, em que constavam 743 casos. Para a coleta, fez-se fotocópia do material, e criaram-se categorias, sendo o método a análise de conteúdo (BARDIN, 1977/2011). A coleta do material ocorreu nos meses de junho a julho de 2011, nos turnos matutino e vespertino.

\section{Análise e Discussão dos Resultados}

Para conhecer a representação da infância indócil no espaço escolar, efetuou-se o seguinte questionamento: quais são os comportamentos apresentados pelos alunos indóceis no espaço escolar que geraram registros nos livros de ocorrência? Os comportamentos apresentados no espaço escolar pelos alunos indóceis envolvendo a utilização de objetos concretos foram: "atirar pedras"; "atirou uma pedra na testa de um colega"; "jogou uma pedra no colega"; "jogando pedra e acertaram o carro"; e "quebrou o vidro de um Monza com uma pedra".

Existem, também, aqueles objetos que estão disponíveis no espaço da sala de aula, para o exercício da atividade docente, tais como apagador, cadeiras, estojos, colas, tesouras e lápis, e que foram utilizados com outras finalidades: "jogaram apagador na cabeça do colega", "se jogando tesouras", "machucou o colega com o lápis", "atirando estojo no colega", "quebrou uma cadeira ao jogar no aluno", "jogou sacola no ventilador", "coloca cola nas portas", "jogando-se cadeiras e classes", "estourando bombinhas" e "quebrou o bebedouro". Logo, atirar, jogar, bater, machucar, quebrar, agredir, brigar, colocar e estourar são alguns dos comportamentos dos alunos indóceis que estão registrados nos livros.

Quanto aos comportamentos apresentados em sala de aula entre alunos indóceis, que não foram executados com o auxílio de objetos, destacam-se as agressões físicas entre alunos: "tapa no olho", "pisaram nos seus dedos da mão", "deu um empurrão", "deu um soco", "com socos agredindo", "mordeu a colega", "deu um tapa", "deu um tombo", "um chute na boca e soco na testa", "um soco na boca", "dando gravatada", "esganou o pescoço", "o aluno agrediu colega... sangrou", "mordeu a orelha do colega", "coices no colega", "bateu no rosto", "foi agredido pela colega a chutes", "agressões (coices)", "agrediram com socos", "dando pontapé", "se embolaram no chão", "cuspiu no colega", "deu um coice" e "pegou-a pelo pescoço".

Os comportamentos apresentados em sala de aula pelos alunos indóceis, tais como dar tapas, pisar, empurrar, dar socos, morder, chutar, esganar, bater, dar "gravatada", dar coices e cuspir, foram os motivadores de seus encaminhamentos ao Serviço de Orientação Educacional (SOE). Em relação aos comportamentos dos alunos indóceis direcionados aos professores, 
que envolvem agressão, podem-se citar agressão verbal manifestada por meio de ofensas ("chamou a professora de imbecil"), ameaça de agressão física ("aluno ameaça professora diz que vai dar um soco", "tentou agredir a vice-diretora, segurou-a pelo braço"), agressões físicas de fato ("bateu no braço da professora") e ameaças de morte ("ameaça... assassinar a professora").Já quanto às representações que envolvem desrespeito, identificaram-se: "falta de respeito com professor", "desrespeito ao professor", "não respeita professores", "desrespeito à professora", "perde o respeito pela professora", "desrespeitou as professoras", "não respeitam o professor" e "faltou com respeito ao professor".

Quanto ao desrespeito, para que fosse possível efetuar uma análise mais profunda, os comportamentos dos alunos deveriam ter sido registrados levando em consideração fatores como: de que forma faltou com respeito?; o que é faltar com respeito com o professor?; qual foi a falta de desrespeito?; que resposta o aluno deu ao professor?; e quais ações ocorreram por parte do aluno que motivaram o seu encaminhamento ao SOE?

A realidade identificada nesta pesquisa, com relação às dificuldades e aos desafios que os professores vivenciam em seu dia a dia para o exercício profissional, mostra-se extremamente complexa. Tais questões desafiam a persistência dos mestres (como a violência no espaço escolar) em continuar desenvolvendo seu trabalho.

Diante disso, questiona-se: o que faz estes professores persistirem, ou seja, não abandonarem sua profissão e seus alunos ditos violentos?. A representação de professor constante no Projeto Político Pedagógico (PPP) escolar está longe do professor real. Este vivencia ameaças de agressão física, verbal e de morte, além de uma sobrecarga de trabalho: "professores lotados nessa escola, em sua maioria trabalham 60 horas semanais, sobrando pouco tempo para cuidar de si mesmo", deve ain- da ter disponibilidade "de tempo para realizar a Formação Continuada e participar das reuniões pedagógicas", de modo que, quando porventura surgirem problemas na sala de aula, deve ter "raciocínio rápido para pensar alternativas de soluções", sendo uma dessas alternativas sistemáticas o encaminhamento ao SOE (PPP, p. 8-21).

A representação de professor constante no PPP da escola analisada para exercer a docência com os indóceis escolares é de alguém que tenha equilíbrio psicológico, seja afetivo, solidário e alegre, eduque pelo respeito, exerça a autoridade, tenha esperança e raciocínio rápido, devendo agir em três turnos, com 60 horas de trabalho semanais - trata-se de uma versão do professor Emílio idealizada, de que falava Rousseau.

Um estudo de Eyng, Gisi e Ens (2011, p. 172), sobre representações sociais e violências nas escolas, mostram que os professores "sentem-se impotentes diante das violências talvez porque não saibam como lidar com a questão", sugerindo, quanto à formação inicial $\mathrm{e}$ continuada de professores, que os desafios envolvam "criar condições para a construção de competências que habilitem para a convivência com situações de violência que se apresentam num contexto em que deverão assumir o papel de agentes promotores (as) do diálogo entre as diferenças".

\subsection{Representações sociais e a produção da infância armada no espaço escolar}

Os objetos em posse e retirados dos alunos indóceis são uma constante preocupação, tendo em vista a forma como eles podem ser utilizados dentro de uma sala de aula por crianças e adolescentes. A partir das análises realizadas neste estudo, percebe-se que não há clareza ou distinção quanto aos procedimentos adotados pela escola em relação às situações que envolvem os alunos indóceis, como, por exemplo, quando 
estes levam até a escola objetos considerados armas pela legislação vigente. Nesse contexto, faz-se necessário trazer à tona o conceito de "Ato Infracional".

De acordo com a legislação atual, "considera-se ato infracional toda conduta praticada por criança ou adolescente definida como crime ou contravenção pelo Código Penal brasileiro" (CNJ/ JUS, 2012, p. 12). Dentre os casos de atos infracionais que correspondem a crimes, pode-se citar: crime contra o patrimônio (furtos, roubos, entre outros); porte ou tráfico de entorpecentes; porte de arma e de explosivo; dano intencional ao patrimônio público ou particular; crime de homicídio; e lesão corporal (CNJ/JUS, 2012).

A Lei n. ${ }^{\circ} 8.069 / 90$, em seu artigo 105 , orienta quanto às situações que envolvem crianças: "atos infracionais praticados por criança corresponderão às medidas previstas no art. $101^{\circ "}$, passíveis, portanto de medidas socioeducativas, sendo consideradas crianças aqueles com até 12 anos incompletos.

Com relação aos objetos apreendidos e/ou achados em sala de aula com os alunos indóceis, alguns são identificados como arma branca: aqueles que são utilizados para outra finalidade que não aquela a qual se destinam originalmente. Nessa categoria, estão inclusos facas, martelos e machados, alguns dos quais foram identificados nos registros dos livros de ocorrência: "o aluno estava com uma faca", "foi pego com uma faca na sala de aula", "estava com um pedaço de faca no bolso", "trouxe um martelinho de ferro", "trouxe um canivete", "foi encontrado com um canivete na sala de aula", "trouxe um estilete", "tinha uma Gilete", "[portava] lâminas de apontador" e "[tinha] cacos de vidro".

Não se pode deixar de destacar o contexto em que estes objetos foram apreendidos: o espaço escolar. $\mathrm{O}$ fato de o objeto ter sido apreendido com o aluno não significa, contudo, que este tenha cometido um ato infracional, mas, sim, infringido as normas disciplinares da escola.
Aquino (1996, p. 40) conceitua indisciplina como "bagunça, tumulto, falta de limites, maus comportamentos, desrespeito às figuras de autoridade, etc". O entendimento do autor sobre a indisciplina traz várias inquietações, ainda sem respostas: qual o papel da família no processo educativo de seus filhos sobre o tema da violência? Quais políticas públicas deveriam ser propostas para a educação tendo em vista a presença de uma infância armada no espaço escolar? Que aspectos devem ser discutidos na formação (inicial e continuada) de professores para trabalharem em situações que envolvem a infância armada? Com que objetivos alunos dos anos iniciais levam facas, canivetes e cacos de vidro para a escola? No entanto, a criação e produção no espaço escolar de uma nova representação social, com o deslocamento e a passagem de indisciplinados a infratores, podem ser capturas pelos instrumentos jurídicos especialmente construídos para esse fim. Diante disso, diversas pesquisas têm sido desenvolvidas recentemente sobre a juventude infratora, propondo aproximações desse tema com o fenômeno do bullying (SALGADO, 2010; MENEZES, 2010; LEÃO, 2012; BINSFELD, 2012; BERNARDI, 2011; ROLIM, 2008).

\subsection{Representações sociais e a infân- cia infratora: a produção do fenôme- no bullying}

No contexto atual, a mídia tem se voltado constantemente para a questão da infância infratora ${ }^{4}$, com matérias que ilustram o tema: "Filho da Rua"; "Menino de 11 anos em cela comum"; "Menino que atirou em professora e depois se matou é enterrado no ABC"; "Meninos condenados $^{5}$ : 1.500 anos de cadeia"; "Meninos do crime"; "11 anos e 7 acusações de roubo"; "Aos 12 anos comandava uma quadrilha"; e "Aos 11 anos roubou 10 ca-

4 Ver, por exemplo, os jornais: Zero Hora (24/01/2012, 23/01/2012 a 03/02/2012 e 17/06/2012); Expresso Ilustrado (09/09/2011); Estadão (23/09/2011); e Programa Fantástico/Rede Globo (31/08/2008). 5 Esta chamada jornalística abre uma série de reportagens diárias veiculadas durante 12 dias. 
sas". Esse discurso midiático não é parte somente da realidade brasileira.

Uma pesquisa realizada em Portugal em 2009, contemplando dez jornais de circulação nacional, sobre os discursos da mídia relacionados com a justiça de crianças e jovens, mostrou que a delinquência e a violência escolar ocupam o terceiro lugar em termos de interesse de publicações da mídia: "A delinquência, é a única que remete para o jovem enquanto agressor... Os casos de delinquência tiveram, por um lado, uma cobertura regular de delitos cometidos ao longo do ano (em geral ou mais especificamente na escola)" (SANTOS, 2010, p. 57).

Os espaços que deveriam ser ocupados pelas crianças, criados pelos adultos para educá-las, têm chamado a atenção da mídia, a qual busca dar visibilidade e produção a novas representações. Em nossa sociedade, as representações são construídas por cientistas, jornalistas, técnicos e políticos ao produzirem os seus discursos, os quais passam a ser publicados em artigos, livros e conferências, com uma linguagem que em seu conjunto parece

participar de um "mundo do discurso" construído a partir de materiais cuidadosamente controlados segundo regras explicitas de que somos o objeto, com os nossos problemas, o nosso futuro e, em definitivo, tudo o que existe como nós. Mas esses relatos estão ao mesmo tempo muito próximos porque nos dizem respeito, suas observações interferem com as nossas próprias observações, e suas linguagens ou suas noções, elaboradas a partir de fatos que nos são estranhos e, por vezes, estranhos continuam a ser-nos, fixam a nossa atenção... (MOSCOVICI, 1978, p. 52, grifo do autor).

Sendo assim, a infância indócil escolar torna-se próxima, e os olhares se voltam para um novo fenômeno, produzido em nível mundial, que tem como foco principal a infância: o bullying ${ }^{6}$.

6 Disponível em: http://revistaescola.abril.com.br/crianca-e-adolescente/ comportamento/bullying-escola-494973.shtml.
Esse fenômeno "se caracteriza por agressões intencionais, verbais ou físicas, feitas de maneira repetitiva, por um ou mais alunos contra um ou mais colegas". O termo, originário da palavra inglesa bully, ainda sem definição em português, significa brigão ou valentão, incluindo comportamentos que envolvem ameaças, tirania, opressão, intimidação, humilhação e maus-tratos. Seu surgimento data da década de 70 .

Um dos pioneiros nos estudos sobre bullying foi o professor Dan Olweus, da Noruega, quando desenvolveu pesquisas solicitadas pelo Ministério da Educação sobre bullying tema em virtude do suicídio de três adolescentes. Os resultados da pesquisa de Olweus influenciaram governos de diversos países para a prevenção da delinquência e violência juvenil (ROLIM, 2008; SALGADO, 2010; MENEZES, 2010; LEÃO, 2012: BINSFELD, 2012; BERNARDI, 2011).

Nesse cenário, pode-se afirmar que a mídia exerce um papel fundamental na construção das representações sociais sobre o fenômeno da delinquência juvenil, visto que "fomenta um sentimento de insegurança das populações, por outro lado, o seu discurso é grandemente responsável pela construção da juventude como uma categoria problemática", podendo produzir discriminação e preconceito, realidade que, na realidade europeia, "é, muitas vezes, tratada como rotina, através de pequenas notícias abreviadas e impessoais" (SANTOS, 2010, p. 36).

As representações podem ser compreendidas como formas de conhecimento do senso comum, devem ter um sujeito e um objeto, e as características de ambos devem se manifestar na representação. Os sujeitos são os professores, ou seja, aqueles que constroem e expressam suas representações, a partir de modelos internalizados, de alguém ou de alguma coisa, ou seja, dos objetos, que, neste caso, são os alunos (Moscovici, 1978). 
Como os professores produzem representações dos alunos encaminhados ao SOE é uma das questões que interessam neste estudo. O aluno real, representado pelos professores e registrado nos livros de ocorrência, é aquele que apresenta comportamentos de atirar, jogar, bater, machucar, quebrar, agredir, brigar, colocar e estourar, isto é, de um aluno que está muito aquém daquele modelo internalizado pelo professor em sua formação inicial: o dócil e fácil de educar, o Emílio de Rousseau. Talvez, o real esteja mais próximo ao menino selvagem, Victor de Aveyron, encontrado nas florestas ao sul da França, cujas tentativas vãs de tratamento e educação, propostas pela medicina da época e desenvolvidas pelo jovem médico Itard, foram frustradas, causando a desistência e o abandono do caso.

O aluno dócil e sociável, existente apenas na versão de Rousseau, contribuiu para o surgimento de uma área especifica do saber, a Educação Especial. Nesse contexto, tais comportamentos, estranhos ao professor, levaram à atitude inicial de retirar os alunos da sala de aula e encaminhá-los ao SOE, o que representa um dos primeiros passos de um processo de exclusão. Logo, questiona-se: seriam estes educáveis ou ineducáveis? Qual área pretende dar conta destes alunos?

Em âmbito internacional, a infầncia vem tendo maior visibilidade, sobretudo com o reconhecimento do bullying, e o espaço escolar, foco da mídia, parece ser o local mais propício para sua criação e produção, com a construção de todo um aparato jurídico psicossocial para sua captura. Sendo a escola um espaço pensado e construído socialmente pelos adultos, voltada para a educação da infância, cabe questionar: para qual infância volta-se esse espaço? Para o aluno ideal? E o aluno indócil, a quem cabe educar? $\mathrm{O}$ aluno, ao manifestar comportamentos indesejáveis e intoleráveis em sala de aula, é encaminhado ao SOE pelo professor, onde é ouvido e, dependendo do fato ocorrido, suspenso, excluído ou transferido.

No Brasil, uma recente pesquisa do Conselho Nacional de Justiça (CNJ), que orienta a política judiciária, emitiu relatório elaborado sobre o perfil de 17,5 mil jovens infratores, os quais cumprem medidas socioeducativas de internação: "O diagnóstico traçado pelo CNJ servirá de base para a definição de Políticas capazes de garantir aos jovens sob custódia do Estado os direitos previstos no ECA e no Sistema Nacional de Atendimento Socioeducativo [SINASE]". Esta pesquisa apresenta uma realidade preocupante e sombria, ou seja, a judicialização da infância, com início das infrações na faixa etária de sete anos, o que vai ao encontro dos dados empíricos fornecidos pelo Conselho Tutelar de Santa Maria, Rio Grande do Sul, em 2008.

Percebe-se, assim, a existência de um sistema de produção e representação da infầncia infratora. Nesta pesquisa, a representação do indócil escolar presente nos livros de registro de ocorrência indica um aluno que "atira, joga, bate, machuca, quebra, agride, briga, estoura" (SPINK, 1993). Identifica-se uma representação da infância armada no espaço escolar, cuja participação da mídia para sua captura e renomeação é fundamental.

Quanto aos procedimentos frequentes adotados pela escola em relação aos alunos indóceis encaminhados ao SOE, esta pesquisa mostra que a suspensão foi o primeiro procedimento adotado, seguida do ato de chamar a Brigada Militar e da transferência de escola. Nesse sentido, afastar o aluno, por meio da suspensão de dois, três, cinco ou sete dias, da escola promove uma exclusão de forma lenta, que não chama tanto a atenção.

Nesse sentido, evidencia-se que não há problematização na educação sobre os aspectos em relação ao desenvolvimento cognitivo da infância indócil, que é afastada e/ou excluída da escola. Causa estranheza o silêncio de professores, educadores e pesquisado- 
res sobre o tema da exclusão da infância indócil. Se, na atualidade, a inclusão de pessoas com deficiência é uma realidade já concretizada e melhor aceita, seja via legislação ou não, os olhares para a infância indócil permanecem negligenciados e carecem de políticas públicas.

\section{Considerações Finais}

Sendo a infância uma construção social, no contexto atual, já não são mais os alunos com deficiência os excluídos do espaço escolar. Estes, a partir de legislação própria, passaram a ser incluídos e mais bem aceitos no sistema educacional.

Os resultados aqui apresentados evidenciam que as questões envolvendo a infância indócil são de âmbito comportamental, e não cognitivo. O indócil escolar está representado como aquele que: atira, joga, bate, machuca, quebra, agride, briga, estoura, rouba, foge, depreda e porta arma, não respeitando as regras. Não foram evidenciados casos em que ambos os aspectos (comportamental e cognitivo) estivessem presentes nos registros, o que implica um deslocamento e uma nova representação formada: na atualidade saem de cena os alunos com problemas de aprendizado, bem como os transtornados e hiperativos medicados, para dar lugar aos indóceis escolares, os quais, provavelmente, irão fomentar a instância jurídica, com a já produzida infância infratora, observada pelos holofotes da mídia. Esta vem sistematicamente divulgando e propagando reportagens sobre a infância infratora, categoria que está relacionada com o surgimento e a explosão de um novo fenômeno vivenciado em âmbito internacional, o bullying.

As medidas e os procedimentos adotados pela escola em relação à infância indócil incluem exclusão de forma fracionada; ameaças de exclusão, representadas na forma de transferência dirigida para outra escola; ameaça de exclusão de projetos sociais; negação do direito de assistir às aulas de deter- minadas disciplinas (Educação Física e Informática); corte de atividades de lazer (recreio); e ameaças de encaminhamento à Promotoria e ao Conselho Tutelar. No entanto, as produções dos indóceis escolares, representados por aqueles alunos que descumprem regras de convivência socialmente construídas, passam a dar visibilidade a uma questão atual e complexa: a representação de uma infância perigosa, armada e infratora, representada e propagada pela mídia e divulgada com o fenômeno do bullying.

Diante disso, cabe mencionar que, segundo Moscovici (1978, p. 174), as representações sociais somente surgem "onde houver perigo para a identidade coletiva, quando a comunicação de conhecimentos submerge as regras que a sociedade se outorgou". Ao ser negado à infância indócil o direito a educação, estando fora do sistema escolar, cria-se uma situação de vulnerabilidade social ainda maior.

Ademais, políticas públicas específicas para a educação e permanência dessas crianças na escola, juntamente com discussões sobre a formação de professores, são fatores urgentes, visto que a escola ainda utiliza métodos e técnicas punitivas, ameaçadoras e excludentes, o que indica o total despreparo para o trabalho com este público. Ressalta-se, nesse sentido, que uma abordagem interdisciplinar pode abrir caminhos e possibilidades, visando contribuir para as discussões e pesquisas sobre essa temática, contribuindo, assim, para a permanência desses alunos na escola e minimizando impactos da exclusão escolar.

\section{Referências}

AQUINO, J. G. Indisciplina na escola: alternativas teóricas e práticas. São Paulo: Summus, 1996.

ARIÉS, P. História social da criança e da família. Rio de Janeiro: LTC, 1981. 
BANKS-LEITE, L. GALVÃO, I. (Org). A Educação de Um Selvagem: as experiências pedagógicas de Jean Itard. São Paulo: Cortez, 2000.

BARDIN, L. Análise de conteúdo. Trad. Luiz Antero e Augusto Pinheiro. São Paulo: Martins Fontes, 1977.

BARDIN, L. Análise de conteúdo. Trad. Luiz Antero e Augusto Pinheiro. São Paulo: Ed. 70, 2011.

BARKLEY, A. R. Transtorno de Déficit de Atenção Hiperatividade (TDAH). Porto Alegre: ARTMED, 2002.

BERNARDI, C. H. Representações Sociais de Bullying por Professores. Disponível em: >http://portal.estacio. br/media/3485743/cristina-helena-bernardin-completa.pdf $<$ Acesso em: 10/11/2011.

BINSFELD, A. R. Bullying: um estudo sobre papéis sociais, ansiedade e depressão no contexto escolar. Disponível em: http://abpri.files.wordpress. com/2010/12/interpersona-41_4.pdf Acesso em: 10/04/2012.

BRASIL, Conselho Nacional de Saúde. Diretrizes e Normas Regulamentadoras de pesquisas envolvendo seres humanos. Resolução CNS no 196/96, Brasília, 1996.

. Ministério da Justiça. Estatuto da Criança e do Adolescente. Lei n. 8.069, de 13 de julho de 1990. Brasília/DF.

. Ministério da Educação. Diretrizes Nacionais para a Educação Especial na Educação Básica. Secretária de Educação Especial - MEC; SSSP, 2001.

. Ministério da Educação. Números da Educação Especial no Brasil. 2006. Disponível em: http://portal. MEC.gov.Br/SEESP. Acesso em: 05 nov. 2010.

BRASIL, Panorama Nacional: a execução das medidas socioeducativas de Internação. Conselho Nacional de Justiça. Brasília, 2012
CORAZZA, S.M. História da infância sem fim. Ijuí/RS: UNIJUÍ, 2000.

DEL PRIORE, M. (org.). História das crianças no Brasil. SP: Contexto, 2007.

EYNG, A.M. Violências nas Escolas: Perspectivas Históricas e Políticas. Ijui: UNIJUÍ. 2011.

FOUCAULT, M. Vigiar e Punir. Rio de Janeiro: 30ª ed; Vozes, 1987.

JAEGER, W. Paidéia: a formação do homem grego. São Paulo: Martins Fontes, 2003.

JODELET, D. (Org.). As representações sociais. RJ: UERJ, 2009.

KAPLAN, HAROLD I. Compêndio de Psiquiatria. POA: ARTMED, 2002.

KORCZAK, J. Como amar uma criança. RJ: Paz e Terra, 1997.

LEÃO, L.G.R. O fenômeno Bullying no ambiente escolar. Disponível em: $\quad<$ http://www.faceww.edu.br/ Revista/04/O\%20FE:<http://www. faceww.edu.br/Revista/04/O\%20 FEN\%C3\%94MENO\%20BULLYING\%2ONO\%20AMBIENTE\%20ESCOLAR\%2o-\%201eticia\%20gabriela. pdf $<$. Acesso em: 30/03/2012.

LUFT, S. Representações sociais das professoras de alunos identificados como hiperativos incluídos no sistema regular de ensino de Santa Maria/RS. 90 p. Dissertação (Mestrado em Educação) - UFSM, Santa Maria/RS, 2007.

MAZZOTTA, M.J.S. Educação Especial no Brasil: História e Políticas Públicas. São Paulo: Cortez, 2005.

MANACORDA, M. A. História da Educação: da antiguidade aos nossos dias. São Paulo: Cortez, 2006.

MEDEIROS, F. M. Direito Processual Penal. Aspectos Históricos. Conceito. Fundamental e Complementar. Denominações. Instrumentalidade. In: Âmbito Jurídico, Rio Grande, $\mathrm{n}^{\circ} 27$ de 31/03/2006. Disponível em: http:// www.ambito=jurídico.com.br/site/in- 
dex.php?n_link=revista_artigos_leitura\&artigo_ $\overline{\mathrm{i} d}=1017$. Acesso em: $\overline{13} \mathrm{dez}$. 2011.

MENEZES, J. A. F. Estudo sobre o fenômeno Bullying e suas repercussões sócio educacional. Disponível em: http://www.ufpe.br/ce/images/Graduacao pedagogia/pdf/2009.1/estudo $\% 20$ sobre $\% 20 \%$ fenomeno $\% 2$ bullying $\% 20$ e\%20suas\%20repercussoes\%20cielo. pdf. Acesso em 30/03/2011.

MOSCOVICI, S. A representação social da psicanálise. Rio de Janeiro: Vozes, 1978.

MOSCOVICI, S. Representações Sociais: investigações em Psicologia Social. Petrópolis/RJ. Vozes, 2010.

NAUJORKS, M. I. (Org). Pesquisa em Educação Especial: o desafio da qualificação. Bauru/SP: EDUSC, 2001.

O.M.S. (Organização Mundial de Saúde). Classificação de transtornos mentais e de comportamento da C.I.D. - 10 (descrições clínicas e diretrizes diagnósticas). Porto Alegre: ARTMED, 1993.

PASSETTI, E. Crianças carentes e políticas públicas. In: Priore, M.D (Org.).

História das crianças no Brasil. São Paulo: Contexto, 2007.

PATTO, M.H.S. A produção do fracasso escolar. São Paulo: Queiroz, 1996.

POSTMANN, N. O. Desaparecimento da infância. RJ: Graphia, 1999.

RIZZINI, I; PILOTTI, F. (Orgs.). A arte de governar crianças: a história das políticas sociais, da legislação e da assistência à infância no Brasil. $2^{\mathrm{a}}$ ed. São Paulo: Cortez, 2009.

ROHDE, L.A.P.; BENCZIK, E.B.P. Transtorno de Déficit de Atenção/Hiperatividade: O que é? Como ajudar? Porto Alegre: ARTMED, 1999.

ROHDE, L.A.P.; MATTOS, P. et al. Princípios e práticas em TDAH. Porto Alegre: ARTMED, 2003.
ROHDE, L.A.P. et al. Transtorno de déficit de atenção/hiperatividade na infância e na adolescência: considerações clínicas e terapêuticas. Revista de Psiquiatria Clínica, v.31 (3); p.124-131, 2004.

ROLIM, M. Bullying: o pesadelo da escola um estudo de caso e notas sobre o que fazer. Dissertação (Mestrado em Sociologia) Universidade Federal do Rio Grande do Sul, UFRGS, Porto Alegre, 2008.

ROUSSEAU, J.J. (tad. MILLIET, S) Emílio ou da educação. São Paulo: Difel 1979.

SANTOS, M. A. Criança e criminalidade no início do século. In: DEL Priore, M.D (Org.). História das crianças no Brasil. São Paulo: Contexto, 2007.

SANTOS, B. S.. Entre a Lei e a Prática: Subsídios para uma reforma da Lei Tutelar educativa. Portugal: 2010.

SALGADO, G.M. O Bullying como prática de desrespeito social: um estudo sobre a dificuldade de lidar com o bullying escolar no contexto do Direito. Disponível em http://www.ambito-jurídico.com.br/site/index.php?n_link=revista_artigos_leitura\&artigo_ $\overline{\mathrm{i}} \mathrm{d}=8172$. 2010.

SASSAKI, R.K. Inclusão: Construindo uma sociedade para todos. Rio de Janeiro: WVA, 1997.

SILVA, A. B. B. Bullying - mentes perigosas nas escolas. São Paulo: Fontanar, 2010.

TEZZARI, M. L. Educação Especial e ação docente: da medicina à educação. Tese (Doutorado em Educação). Universidade Federal do Rio Grande do Sul, UFRGS, Porto Alegre, 2009.

WINNICOTT, D. W. Privação e delinquência. São Paulo/SP. Ed.: Martins Fontes, 2005. 